\title{
Dual RAS blockade—unresolved controversy?
}

\author{
Harikrishna Makani, Franz H. Messerli, Sripal Bangalore, Kavit A. Desouza, Arpit Shah and Johannes F. E. Mann
}

We read with interest the News \& Views commentary by Piero Ruggenenti and Giuseppe Remuzzi (Ruggenenti, P. \& Remuzzi, G. Meta-analyses can misdirect decisions on treatment. Nat. Rev. Nephrol. 9, 311-312; 2013), ${ }^{1}$ which was written in response to our meta-analysis that compared the efficacy and safety outcomes of dual renin-angiotensin system (RAS) blockade with that of monotherapy in 68,405 patients with hypertension, diabetes or proteinuria. ${ }^{2}$ RAS inhibition using angiotensin-converting enzyme (ACE) inhibitors or angiotensinreceptor blockers (ARBs) versus other antihypertensive agents has unequivocally been shown to reduce renal outcomes in patients with proteinuria., Many researchers, including ourselves and Remuzzi's team, have hypothesized that more intense RAS inhibition using more than one RAS blocker versus a single agent would offer more benefit in patients with proteinuric renal disease. However, our meta-analysis showed that dual RAS blockade compared with monotherapy failed to reduce mortality and was associated with an excessive risk of adverse events. ${ }^{2}$

Ruggenenti and Remuzzi suggest that the lack of benefit of dual versus single RAS blockade in our meta-analysis could be due to the inclusion of the ALTITUDE trial, ${ }^{5}$ which evaluated an aliskiren-based regimen. However, even after excluding ALTITUDE we found no difference in all-cause mortality $(P=0.35)$ and cardiovascular mortality $(P=0.15)$ between the dual RAS blockade and monotherapy groups. Despite a significant fall in blood pressure, aliskiren conferred no benefit in terms of risk of stroke in the ALTITUDE 5 trial and no such benefit has been shown with ACE inhibitor plus ARB combinations. ${ }^{6}$ Thus we disagree with the authors that aliskiren-based combinations are associated with an increased stroke risk.

Ruggenenti and Remuzzi also emphasized that a $23 \%$ reduction in heart failure hospitalizations and cardiovascular mortality was reported in patients with heart failure who were treated with dual RAS blockade compared with monotherapy in the CHARM-Added trial. ${ }^{7}$ However, at least two studies (VALIANT ${ }^{8}$ and Val-HeFT ${ }^{9}$ ) failed to show any benefit of dual RAS blockade with respect to all-cause mortality and cardiovascular mortality in patients with heart failure.

The criticism that we included heterogeneous trials in our meta-analysis is pertinent to any such analysis and is inevitable; short-term studies with small sample sizes have to be included in meta-analyses to address safety aspects. However, the few hard outcomes in the small trials that we included would not materially alter our summary data on major outcomes from large randomized controlled trials. Ruggenenti and Remuzzi suggest that safety outcomes were worse in the dual RAS blockade group only because patients with renal failure and nephropathy were included in our analysis. To answer this question, we analyzed published data on the risk of hyperkalaemia, hypotension and renal failure in patients treated with dual RAS blockade after excluding all studies that included patients with renal failure, diabetic nephropathy or microalbuminuria at baseline. We also excluded studies that used aliskiren-based combinations to further show that these therapies have similar event rates to ACE inhibitor and ARB combinations. We found that the relative risk of adverse events associated with dual RAS blockade significantly increased after patients with nephropathy were excluded, and increased further after those who received aliskiren-based therapies were excluded (Table 1).

We are surprised that Ruggenenti and Remuzzi state that "compared with singledrug RAS blockade, dual therapy more effectively reduced ... proteinuria in patients

Table 1 | Risk of adverse events in patients receiving dual versus single-agent RAS blockade

\begin{tabular}{|c|c|c|c|c|}
\hline Safety outcome & $\begin{array}{l}\text { No. of } \\
\text { studies }\end{array}$ & $\begin{array}{l}\text { Total no. } \\
\text { of patients }\end{array}$ & $\begin{array}{l}\text { Relative risk of } \\
\text { outcome }(95 \% \mathrm{Cl})\end{array}$ & $P$ value \\
\hline \multicolumn{5}{|l|}{ Hyperkalaemia } \\
\hline Overall & 23 & 60,638 & $1.55(1.32-1.82)$ & $<0.0001$ \\
\hline $\begin{array}{l}\text { After excluding studies that included patients } \\
\text { with nephropathy at baseline }\end{array}$ & 17 & 50,760 & $1.64(1.30-2.08)$ & $<0.0001$ \\
\hline $\begin{array}{l}\text { After excluding studies that included patients } \\
\text { with nephropathy at baseline and studies of } \\
\text { aliskiren-based therapy }\end{array}$ & 7 & 44,422 & $1.72(1.12-2.63)$ & 0.01 \\
\hline \multicolumn{5}{|l|}{ Hypotension } \\
\hline Overall & 18 & 61,252 & 1.66 (1.38-1.98) & $<0.0001$ \\
\hline $\begin{array}{l}\text { After excluding studies that included patients } \\
\text { with nephropathy at baseline }\end{array}$ & 14 & 51,762 & $1.70(1.33-2.16)$ & $<0.0001$ \\
\hline $\begin{array}{l}\text { After excluding studies that included patients } \\
\text { with nephropathy at baseline and studies of } \\
\text { aliskiren-based therapy }\end{array}$ & 10 & 49,359 & $1.83(1.36-2.47)$ & $<0.0001$ \\
\hline \multicolumn{5}{|l|}{ Renal failure } \\
\hline Overall & 20 & 64,320 & $1.41(1.09-1.84)$ & 0.01 \\
\hline $\begin{array}{l}\text { After excluding studies that included patients } \\
\text { with nephropathy at baseline }\end{array}$ & 12 & 52,335 & $1.83(1.31-2.57)$ & 0.0004 \\
\hline $\begin{array}{l}\text { After excluding studies that included patients } \\
\text { with nephropathy at baseline and studies that } \\
\text { included patients with nephropathy }\end{array}$ & 6 & 48,732 & $1.96(1.31-2.94)$ & 0.001 \\
\hline
\end{tabular}


with renal disease, an effect that translated into almost complete protection against progression to ESRD [end-stage renal disease]." Such a general statement (that is, "renal disease" and "almost complete protection") is not supported by controlled data and is contradicted by our meta-analysis and by major trials with renal outcomes, including ORIENT, ${ }^{10}$ ONTARGET, ${ }^{11}$ ALTITUDE, ${ }^{5}$ and VA-NEPHRON-D. ${ }^{12}$ The VA-NEPHRON-D trial was stopped prematurely because of a lack of efficacy and increased incidence of adverse events in the ACE inhibitor plus ARB group, ${ }^{12}$ which was consistent with the results of the other three outcome trials listed above. Reference of Ruggenenti and Remuzzi to their finding that dual therapy resulted in almost complete protection against progression to ESRD ${ }^{13}$ seems to be contradicted by the ever increasing number of patients who present with ESRD despite increasing use of dual RAS blockade. We are also puzzled by the co-mingling in their arguments of hard outcomes and surrogate end points, such as proteinuria. When hard outcomes are available - as was the case in the data we analyzed-therapeutic decisions should no longer be based on surrogate end points.

Ruggenenti and Remuzzi also imply that hyperkalaemia should be redefined in people with renal disease such that serum potassium concentrations $\geq 5.5 \mathrm{mM}$ are not considered abnormal. We are unaware of data that support this notion. The risks associated with hyperkalaemia are evident from populationwide data from Ontario, which showed that an increase in the prescription of spironolactone for heart failure resulted in a marked increase in hyperkalaemia-associated morbidity and mortality. ${ }^{14}$

In summary, although proteinuria is an outstanding marker for renal risk, reduction of proteinuria by various measures, short of bilateral nephrectomy, does not unequivocally lead to renal protection. Inhibition of the RAS using an ACE inhibitor or an ARB does offer such protection but dual RAS blockade does not seem to result in additional benefit. We invite Ruggenenti, Remuzzi and colleagues to initiate randomized controlled trials to determine in which, if any, clinical situation the beneficial effects of dual RAS blockade on hard renal outcomes might outstrip the well-documented risk of adverse events.

St Luke's Roosevelt Hospital, Columbia University College of Physicians \& Surgeons, 1111 Amsterdam Avenue, New York, NY 10019, USA (H. Makani, F. H. Messerli, K. A. Desouza, A. Shah). New York University School of Medicine, 550 First Avenue, New York, NY 10016, USA (S. Bangalore). Munich General Hospitals, Kölner Platz 1, 80804 Munich, Germany (J. F. E. Mann).

Correspondence to: F. H. Messerli

messerli.f@gmail.com

\section{Competing interests}

F. H. Messerli has consulted for Abbott, Bayer, Daiichi Sankyo, Gilead, Ipca Laboratories Ltd, Medtronic, Novartis, Pfizer, PharmApprove, Servier and Takeda. S. Bangalore is a member of the advisory boards of Boehringer Ingelheim, Daiichi Sankyo and Pfizer. J. F. E. Mann has received honoraria or research funding from Abbott, Actelion, Amgen, Bayer, Boehringer-Ingelheim, Novo-Nordisk and Roche. H. Makani, K. A. Desouza and A. Shah declare no competing interests.

1. Ruggenenti, P. \& Remuzzi, G. Renin-angiotensin system: meta-analyses can misdirect decisions on treatment. Nat. Rev. Nephrol. 9, 311-312 (2013).

2. Makani, H., Bangalore, S., Desouza, K. A., Shah, A. \& Messerli, F. H. Efficacy and safety of dual blockade of the renin-angiotensin system: meta-analysis of randomised trials. BMJ 346 , f360 (2013).
3. Kunz, R., Friedrich, C., Wolbers, M. \& Mann, J. F. Meta-analysis: effect of monotherapy and combination therapy with inhibitors of the renin angiotensin system on proteinuria in renal disease. Ann. Intern. Med. 148, 30-48 (2008).

4. Casas, J. P. et al. Effect of inhibitors of the renin-angiotensin system and other antihypertensive drugs on renal outcomes: systematic review and meta-analysis. Lancet 366, 2026-2033 (2005).

5. Parving, H. H. et al. Cardiorenal end points in a trial of aliskiren for type 2 diabetes. N. Engl. J. Med. 367, 2204-2213 (2012).

6. Mann, J. F. et al. Dual inhibition of the reninangiotensin system in high-risk diabetes and risk for stroke and other outcomes: results of the ONTARGET trial. J. Hypertens. 31, 414-421 (2013).

7. McMurray, J. J. et al. Effects of candesartan in patients with chronic heart failure and reduced left-ventricular systolic function taking angiotensin-converting-enzyme inhibitors: the CHARM-Added trial. Lancet 362, 767-771 (2003).

8. Pfeffer, M. A. et al. Valsartan, captopril, or both in myocardial infarction complicated by heart failure, left ventricular dysfunction, or both. N. Engl. J. Med. 349, 1893-1906 (2003).

9. Cohn, J. N. \& Tognoni, G. A randomized trial of the angiotensin-receptor blocker valsartan in chronic heart failure. N. Engl. J. Med. 345, 1667-1675 (2001).

10. Imai, E. et al. Effects of olmesartan on renal and cardiovascular outcomes in type 2 diabetes with overt nephropathy: a multicentre, randomised, placebo-controlled study. Diabetologia 54, 2978-2986 (2011).

11. Mann, J. F. et al. Renal outcomes with telmisartan, ramipril, or both, in people at high vascular risk (the ONTARGET study): a multicentre, randomised, double-blind, controlled trial. Lancet 372, 547-553 (2008).

12. Fried, L. F. et al. Design of combination angiotensin receptor blocker and angiotensinconverting enzyme inhibitor for treatment of diabetic nephropathy (VA-NEPHRON-D). Clin. J. Am. Soc. Nephrol. 4, 361-368 (2009).

13. Ruggenenti, P. et al. Role of remission clinics in the longitudinal treatment of CKD. J. Am. Soc. Nephrol. 19, 1213-1224 (2008).

14. Juurlink, D. N. et al. Rates of hyperkalemia after publication of the Randomized Aldactone Evaluation Study. N. Engl. J. Med. 351, 543-551 (2004). 